\title{
DIFFERENCES IN ACADEMIC RESILIENCY WHEN THE PANDEMIC FORCED COURSES ONLINE: WAS PRIOR ONLINE COURSETAKING PROTECTIVE?
}

Claire Wladis, City University of New York, Alyse C. Hachey, University of Texas at El Paso, Katherine M. Conway, City University of New York, United States of America

\section{Abstract}

We report results from a dataset consisting of all courses taken by students at the City University of New York [CUNY] in fall 2019 and spring 2020. This time frame covers the semester prior to the wide-spread onset of the COVID-19 pandemic in New York City (i.e., pre-pandemic), and the semester when the coronavirus precipitated a rapid and unprecedented forced shift of all courses within the university system to a fully-online mode of instruction early in the term (i.e., pandemic term). Findings indicate that students at two-year colleges, men, and certain racial/ethnic groups had less resilient course outcomes when comparing their rates of pre-pandemic vs. pandemic course outcomes. However, these differences were observed primarily among those students who had not originally chosen to enrol in any fully online courses that year. In contrast, students who had originally chosen to enrol in fully online courses that year were much more resilient, with differences by institution type, gender, and race/ethnicity by and large not exacerbated by the pandemic.

\section{Motivation for the Study}

The question has arisen as to whether the forced shift to online learning due to the pandemic impacted course outcomes differentially for different groups. For example, institution type (two-year vs. four-year) was already a significant predictor of college outcomes pre-pandemic (e.g., NCES, 2020a). Gender and race/ethnicity have also been predictive of outcomes in online courses, as well as college courses more generally (e.g., Johnson \& Mejia, 2014; Xu \& Xu, 2019). It is unclear the extent to which the pandemic has magnified these inequities. It is difficult to tease apart the direct effects of the pandemic from effects of the abrupt mandatory shift to fully online learning, and this is not a causal study; however, we are able to tease apart some of these patterns by considering students separately based on whether they originally chose to enrol in fully online courses prior to the onset of the pandemic. Analysing data collected from the City University of New York 
Wladis, C., Hachey, A. C., \& Conway, K. M.

Differences in Academic Resiliency When the Pandemic Forced Courses Online: Was Prior Online Coursetaking Protective?

[CUNY] provided a unique opportunity to find answers to these questions for three-fold reasons: New York City had the earliest large-scale severe impact from the COVID-19 pandemic in the U.S.; the CUNY student population is large and widely diverse, allowing for in-depth exploration for different student sub-groups; and CUNY provides the same overall context while including both two-year and four-year colleges. Therefore, in this study, we analysed the course outcome data at CUNY for various groups in fall 2019 (pre-pandemic) vs. spring 2020 (when the COVID-19 pandemic forced all students fully online a third of the way into the semester). Research has investigated whether students are at higher risk of failing online courses in comparison to face-to-face courses with mixed results (e.g. Jaggars \& Xu, 2010; Johnson \& Mejia, 2014; Shea, \& Bidjerano, 2014), but it is not even clear the extent to which these findings are relevant to the forced-online experiences of many students during the pandemic, since students who chose to take online courses in the past typically had different characteristics than those who did not, and many of these characteristics correlate with other factors that are also related to course outcomes (e.g., Giancola et al., 2009; Johnson \& Mejia, 2014; Xu \& Xu, 2019; Wladis et al., 2018; Wladis, et al., n.d.). Because those who self-select into online courses and those who do not have been found to differ, questions have arisen as to how the forced shift to fully online learning during the pandemic relates to the course outcomes of all types students. This study attempts to address this question.

\section{Theoretical Framework}

This study draws on the concept of resilience, defined as "a phenomenon or process reflecting relatively positive adaptation despite experiences of significant adversity or trauma" (Luthar, 2006; p.6). Resilience has an important role in coping during and after natural disasters and large-scale crises (Bono et al., 2020). In the context of this study, we conceptualize academic resilience as relative-the extent to which a student's course outcomes improved, stayed the same, or worsened during the pandemic term. Evidence relates resilience with socio-demographic factors, employment and academic level, and further, suggests that resilience is malleable to development and improvement through intervention (see review in San Román-Mata et al, 2020).

In addition to the shift to fully online learning, students' resiliency during the pandemic may have been impacted by other factors. Pre-pandemic findings suggest time poverty has a significant relationship with academic momentum, with women, student parents, and minority students generally more time poor (e.g. Wladis et al., 2018). Additionally, pandemic-related stress may have had an impact on students' resiliency (Pariat et al., 2014). Non-traditional students (who, pre-pandemic, enrolled both online and at two-year colleges at higher rates), often face higher levels of external sources of stress (Giancola 
et al., 2009). For two-year college students at CUNY, findings from Manly et al. (2020) indicate the pandemic amplified existing stressors and created new ones and reduced the time available for college. Research with four-year college students suggests that the impact of the pandemic also had mixed effects on time (St. Amour, 2020). Because we are not able to isolate these variables directly, we considered instead comparisons within groups based on prior voluntary online enrolment: differences that persist across both groups of students (those who did and did not originally choose to enrol online) may be more likely to be related to direct impacts of the pandemic; whereas differences that vanish when we look only at students who previously took online courses may be due to the experiences that students had when they were forced into the fully online course mode involuntarily as a result of the pandemic. This allows us to put forth hypotheses about which students were likely most negatively affected by being forced online-while the results are not causal, they may be helpful in generating hypotheses for future causal testing, and they may serve as preliminary guidelines for institutions who are wondering whether future mandatory fully online courses may be detrimental to some student groups or not.

\section{Method}

This study utilizes a dataset consisting of all courses taken by students enrolled in fall 2019 or spring 2020 in the City University New York [CUNY] system, which includes two and four-year colleges (1,564,548 course records taken by 260,784 unique students). We conducted all analyses in Stata, using mixed for multi-level linear probability models and melogit for multi-level logistic regression models. Logistic regression and linear probability multi-level models were run and both approaches rendered similar results. Our multi-level models were comprised of three levels, including individual course record, the particular student and the college the student attended. With $i$ for course records and $j$ for students and $k$ for colleges, our multi-level model is:

Level 1:

$Y_{i j k}=\beta_{0 j k}+\beta_{1 j k} T_{1 i j k}+\cdots+\beta_{n j k} T_{1 i j k}+\varepsilon_{i j k}$

Level 2. For each $\boldsymbol{l}=\mathbf{0}, \ldots, \boldsymbol{n}$ :

$\beta_{l j k}=\tau_{l 0 k}+\tau_{l 1 k} C_{l 1 k}+\cdots+\tau_{l m k} C_{l m k}+u_{l j k}$

Level 3. For each $\boldsymbol{l}=\mathbf{0}, \ldots, \boldsymbol{n}$ and $\boldsymbol{p}=\mathbf{0}, \ldots, \boldsymbol{m}$ :

$\gamma_{l p k}=\mu_{l p 0}+\mu_{l p 1} L_{l p 1}+\cdots+\mu_{l p q} L_{l p q}+r_{l p k}$ 
Where $\beta_{0 j \mathrm{k}}$ are the level-one intercepts, $\beta_{1 j \mathrm{k}}, \ldots, \beta_{\mathrm{n} j \mathrm{k}}$ are the level-one slopes, and $\varepsilon_{i j k}$ represents the random effect for course record $i$, student $j$, and college $k ; \tau_{l 0 k}$; for $l=$ $0, \ldots, n, \tau_{l 0 k}$ are the level-two intercepts, $\tau_{l 1 k}, \ldots, \tau_{l m k}$ are the level-two slopes, and $u_{l j k}$ are the random effects for student $j$ at college $k$; and for $l=0, \ldots, n$ and $p=0, \ldots, m, \mu_{l p 0}$ are the level-three intercepts, $\mu_{l p 1}, \ldots, \mu_{l p q}$ are the level-three slopes, and $r_{l p k}$ are the random effects for college $k$.

\section{Results}

Students at two-year colleges had significantly lower rates of successful course completion (final grade of $\mathrm{C}$ - or better) in comparison to four-year colleges $(\mathrm{p}<0.001)$, which is in line with previous research (e.g., Goodman et al., 2014). They also did significantly worse in the forced-online pandemic term than the pre-pandemic term $(\mathrm{p}<0.001)$. The slope differed significantly for two-vs.-four-year colleges $(\mathrm{p}<0.001)$, with four-year students having more successful course completion during the spring vs. fall term. (see Figure 1.). Thus, fouryear students had significantly more resilient outcomes during the pandemic than twoyear students. Control variables (gender, race/ethnicity, age, G.P.A., first-semester freshman status, median household income of zip code) added to the model reduced the size of the difference but did not eliminate any of the observed patterns or significances.

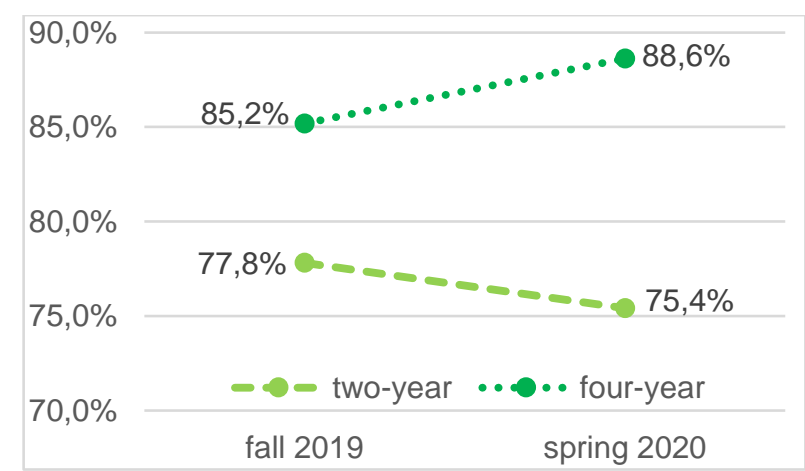

Figure 1. Mean successful course completion rates, by student, two-vs-four year colleges, only those students enrolled both terms

Prior to the pandemic, students were free to opt in or out of online courses and research showed differential rates of online course enrolment by both gender and race/ethnicity, with both women and White students overrepresented online (e.g., Shea \& Bidjerano, 2014; $\mathrm{Xu} \& \mathrm{Xu}, 2019)$. Our next analyses assessed how the forced shift to online learning related to these factors. For students at two-year colleges, women had approximately similar rates of successful course completion both terms, whereas men's course outcomes were significantly worse in spring when all courses were forced online $(p<0.001)$. For students at four-year colleges, both genders were more successful in the pandemic spring term than in fall, but there was still a significant interaction, with women's successful course outcomes increasing more during the pandemic spring term than men's $(p<0.001)$. Thus, 
Wladis, C., Hachey, A. C., \& Conway, K. M.

Differences in Academic Resiliency When the Pandemic Forced Courses Online: Was Prior Online Coursetaking Protective?

at both two-and four-year colleges, women's course outcomes were more resilient during the pandemic than men's course outcomes.

Overall differences in course outcomes by race/ethnicity $(\mathrm{p}<0.001)$ were also found at both two-and four-year colleges. For students attending two-year colleges, Asian/Pacific Islander students had similar course outcomes in fall and spring, while all other student groups (White, Black, Hispanic and American Indian/Native Alaskan) did worse in the spring pandemic term than the pre-pandemic fall [slope differences were statistically significant $(p<0.005)$ ]. In contrast, for students at four-year colleges, all racial/ethnic groups had better outcomes during the spring than in the pre-pandemic fall; however, relative slope patterns were somewhat similar. In one exception, gaps in outcomes between Black or Hispanic vs. White students narrowed slightly during the pandemic spring term.

We explored whether the patterns for gender and race/ethnicity are connected to students' prior online course enrolment, as some research suggests this is a factor (Hachey et al., 2014). Students were classified as "dual-mode" if they had enrolled in at least one online and one face-to-face course in both fall and spring. Students were classified as "traditionalmode" if they enrolled in only face-to-face courses both terms. During the spring pandemic term, even face-to-face courses were forced fully online; we classified students based on their original preferred mode(s), to tease out the relationship between their preferences and outcomes. While there were significant increases in the course outcomes gap between men and women during the pandemic term at both types of colleges for traditional-mode students $(p<0.001)$, results indicate no significant interaction between semester and gender for dual-mode students (see Figure 2). Being a dual-mode student seemed to be protective for men during the spring pandemic term, with traditional-mode men at twoyear colleges having less resilient outcomes in the pandemic term. There were also significant differences in success rates for traditional-mode students at both two-year and four-year by race/ethnicity by term; these differences tended to be less significant among dual-mode students. The patterns found indicate that conditions during the pandemic term (i.e. forced switch to fully online) correlated with increased success and narrowing of outcome gaps for dual-mode students by race/ethnicity, but a negative impact and widening of the success rate for traditional-mode students by race/ethnicity (see Figure 2). 


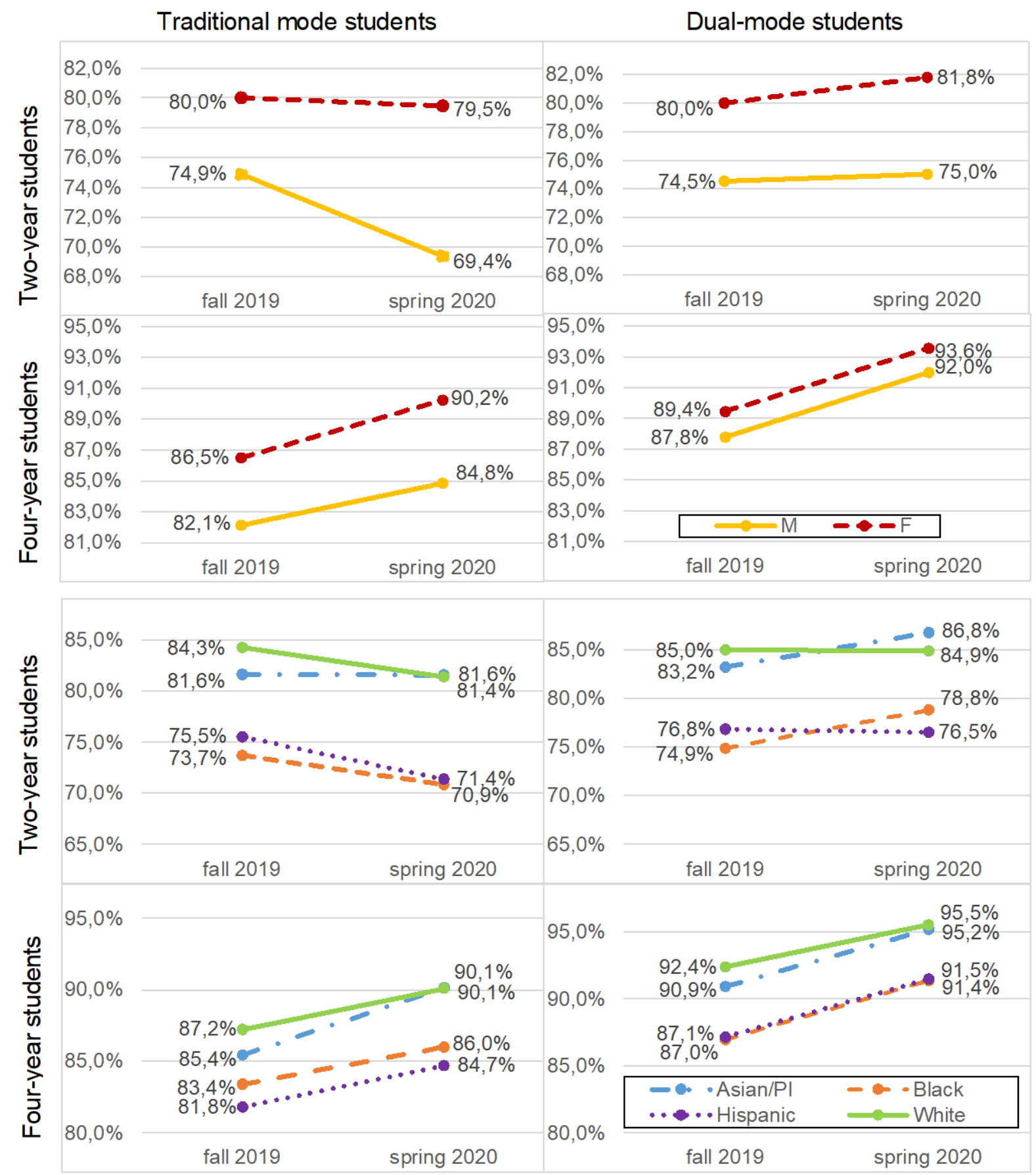

Figure 2. Mean successful course completion, by student, by term, gender or race/ethnicity, and by dual-vs. traditional-mode, at two- vs. four-yr. colleges

\section{Limitations}

CUNY students are highly diverse and thus the results of this study are likely generalizable to a wider population; however, caution should be used before extending findings to other groups (e.g., rural campuses). Gender and race/ethnicity were also recorded in a limited way by the CUNY system. During the study time frame, CUNY had only a binary category for gender (male or female). Thus, the gender categories may not fully represent the ways in which students might identify. CUNY also collects race/ethnicity using limited U.S. 
Wladis, C., Hachey, A. C., \& Conway, K. M.

Differences in Academic Resiliency When the Pandemic Forced Courses Online: Was Prior Online Coursetaking Protective?

federal categories, which likely do not fully represent how many students self-identify, especially those from multiple racial/ethnic groups. We also note that our classification of students as dual vs. traditional mode is an imperfect measure of prior online course enrolment, as this does include traditional students who took an online course prior to the study time frame. However, this classification does accurately reflect student's enrolment preference and online experience immediately prior to the pandemic, and if anything, would likely underestimate rather than overestimate any effects.

\section{Conclusion and Implications}

The higher rates of successful course completion in the spring pandemic term at the fouryear colleges was surprising, given that all of the students in the study were in the same hard-hit pandemic city and in the same university system context. Some preliminary research has suggested that instructors were more lenient in spring during the pandemic (e.g., Lederman, 2020), which might explain these patterns-it may be that this leniency benefitted students at both two- and four-year colleges but was not enough to override other negative factors that may have impacted two-year students more strongly during the pandemic. Two-year colleges are attended by higher proportions of Black and Hispanic students (NCES, 2020b), and in New York City, Black and Hispanic communities were disproportionately more likely to get sick with and die from COVID-19 during the study (Boston Medical Center, 2020). Recent research also indicates that two-year students faced greater time poverty, an upsurge in environmental stressors (particularly financial/housing/food insecurity), and a lack of necessary conditions for online success (i.e., private workspace, Internet access, devices, etc.) in relation to the pandemic (Manley et al., 2020; Garcia et al., 2020; Osborne, 2020). Further, two- and four-year students have different distributions of characteristics to begin with (e.g., parenthood) that correlated with time poverty during the pandemic (Manley et al., 2020), which might have impacted their outcomes. It is also possible that the unexpected success of four-year students is a reflection of less time poverty (i.e., no commute/less work) and more time studying in the spring pandemic term in comparison to the pre-pandemic fall (St. Amour, 2020), compared to two-year students. Although this research is not causal and there are likely many factors influencing the results, our findings do suggest that the pandemic and the related forced shift to online learning may have worsened educational inequities by institution type already present before the pandemic (Fain, 2020).

The patterns found for gender are unexpected, as research (Heggeness \& Fields, 2020) suggests that during the pandemic, women carried the heavier burden of child rearing/home schooling (i.e., higher time poverty); yet it was men (particularly at two-year colleges) who had the worst course outcomes during the spring pandemic term when 
Wladis, C., Hachey, A. C., \& Conway, K. M.

Differences in Academic Resiliency When the Pandemic Forced Courses Online: Was Prior Online Coursetaking Protective?

instruction shifted fully online. This actually reinforces other pre-pandemic research, which shows that women tend to do better than men in college in spite of having more time poverty (Wladis et al., n.d.), and that women are also more likely to enrol in online courses voluntarily, and therefore had on average more experience with them prior to the pandemic (e.g. Johnson \& Mejia, 2014), which may have been a factor. This hypothesis is reinforced by patterns observed after disaggregating dual-mode and traditional-mode students, where the interaction between gender and pre-vs-pandemic term was only significant for traditional mode students, and not for dual mode students. Some gaps by racial/ethnic group expanded on average during the pandemic (e.g., Asian/PI vs. Black, White, or Hispanic students); however, this also seemed to be significantly related to whether students were dual-or traditional-mode. Racial/ethnic gaps remained relatively stable and even shrunk in some cases (e.g., Black vs. White at two-year) among dual-mode students, while they tended to increase among traditional mode students. This suggests that students who previously chose to enrol in online courses were more resilient during the pandemic, across racial groups. This introduces questions about exactly which traits, circumstances, or skills distinguished dual- from traditional-mode students, and how this might inform attempts to improve equity in college outcomes among students by institution type, gender, and race/ethnicity, especially as institutions move to offer more fully online courses. It may be important to investigate possible malleable factors of those who self-select into fully online courses, so institutions could work to better support all students succeed online. Further, since many students who self-select into online courses do so out of a need for flexibility in terms of time and space (Jaggars et al., 2013), it may also be that some students who had already opted to enrol online at the start of the semester were better served when all their courses moved fully online during the spring pandemic term-if this were the case, it would suggest that providing these students with more flexibility to take courses fully online in the future, even after the pandemic is over, might be beneficial. Further causal research is necessary to explore this possibility.

\section{References}

Bono, G., Reil, K., \& Hescox, J. (2020). Stress and wellbeing in college students during the COVID-19 pandemic: Can grit and gratitude help? International Journal of Wellbeing, 10(3), 39-57. doi:10.5502/ijw.v10i3.1331

Boston Medical Center (2020, October 27). Black Hispanic individuals hardest hit by COVID-19: Higher death, hospitalization rates compared to non-white Hispanic individuals, variable by race. ScienceDaily [Blog post]. Retrieved from https:/www.sciencedaily.com/releases/2020/10/201027111229.htm 
Wladis, C., Hachey, A. C., \& Conway, K. M.

Differences in Academic Resiliency When the Pandemic Forced Courses Online: Was Prior Online Coursetaking Protective?

Fain, P. (2020, June 17). Higher education and work amid crisis. Inside Higher Ed [Blog post]. Retrieved from https://www. insidehighered.com/news/2020/06/17/pandemichas-worsened-equity-gaps-higher-education-and-work

Garcia, L. L., Bohling, M., \& Adkins, C. (2020, July 10). The early impacts of COVID-19 on the Community College student experience. Diverse Issues in Higher Education [Blog post]. Retrieved from https://diverseeducation.com/article/183750/

Giancola, J., Grawitch, M., \& Borchert, D. (2009). Dealing with the stress of college a model for adult students. Adult Education Quarterly: A Journal of Research and Theory, 59, 246-263. doi: 10.1177/0741713609331479

Hachey, A. C., Wladis, C. W., \& Conway, K. M. (2014). Prior online course experience and G.P.A. as predictors of subsequent online STEM course outcomes. The Internet and Higher Education, 25, 11-17. doi:10.1016/j.iheduc.2014.10.003

Heggeness, M. L., \& Fields, J. M. (2020, August 18). Working moms bear brunt of home schooling while working during COVID-19. US Census Bureau [Blog post]. https://www.census.gov/library/stories/2020/08/parents-juggle-work-and-child-careduring-pandemic.html

Jaggars, S. S., Edgecombe, N., \& West Stacey, G. (2013). What we know about online course outcomes. Research Review. Community College Research Center, Columbia University. Retrieved from https://ccrc.tc.columbia.edu/media/k2/attachments/whatwe-know-about-online-course-outcomes.pdf

Johnson, H., \& Mejia, M. C. (2014). Online learning and student outcomes in California's community colleges. Public Policy Institute of California. Retrieved from http://www.ppic.org/content/pubs/report/R_514HJR.pdf

Lederman, D. (2020, April 22). How teaching changed in the (forced) shift to remote learning. Inside Higher Ed [Blog post]. Retrieved from

https://www.insidehighered.com/digital-learning/article/2020/04/22/how-professorschanged-their-teaching-springs-shift-remote

Luthar, S. S. (2006). Resilience in Development: A synthesis of research across decades. In D. Cicchetti \& D. J. Cohen (Eds.), Developmental Psychopathology: Risk, disorder and adaptation ( $3^{\text {rd }}$ ed.). Wiley.

Manley, C. A., Wladis, C., Hachey, A. C., \& Karim, S. (2020). Deeper Listening: The unexpected relevance of external stressors and time poverty for online students. Paper presented at the OLC Accelerate Conference, November, Orlando, FL/Virtual.

NCES. (2019). Indicator 23: Postsecondary graduation rates. Retrieved from https://nces.ed.gov/programs/raceindicators/indicator_red.asp 
Wladis, C., Hachey, A. C., \& Conway, K. M.

Differences in Academic Resiliency When the Pandemic Forced Courses Online: Was Prior Online Coursetaking Protective?

NCES (2020a). Undergraduate retention and graduate rates. Retrieved from https://nces.ed.gov/programs/coe/indicator_ctr.asp

NCES. (2020b). Characteristics of Postsecondary Students. The Condition of Education. Retrieved from https://nces.ed.gov/programs/coe/indicator_csb.asp

Osborne, M. (2020, June 1). 8000+ community college students share their COVID-19 stories. EdNC [Blog post]. Retrieved from https://www.ednc.org/nc-communitycollege-students-share-covid-19-impact/

Pariat, L., Rynjah, A., Joplin, M., \& Kharjana, G. (2014). Stress Levels of College Students: Interrelationship between Stressors and Coping Strategies. Journal of Humanities and Social Science, 19(8), 40-46. doi:10.9790/0837-19834046

Shea, P., \& Bidjerano, T. (2014). Does online learning impede degree completion? A national study of community college students. Computers \& Education, 75, 103-111. http://dx.doi.org/10.1016/j.compedu.2014.02.009

San Román-Mata, S., Zurita-Ortega, F., Puertas-Molero, P., Baducu, G., \& GonzálezValero, G. (2020). A predictive study of resilience and its relationship with academic and work dimensions during the COVID-19 Pandemic. Journal of Clinical Medicine, 9(10), 3258. doi:10.3390/jcm9103258

St. Amour, M. (2020, June 23). Report: COVID-19 has hurt college students. Inside Higher Ed (Blog post]. Retrieved from https://www.insidehighered.com/quicktakes/2020/06/23/report-covid-19-has-hurtcollege-students

Wladis, C., Hachey, A. C., \& Conway, K. M. (n.d.). It's about time: The inequitable distribution of time as a resource for college, by gender and race/ethnicity.

Wladis, C., Hachey, A. C., \& Conway, K. M. (2018). No time for college? An investigation of time poverty and parenthood. Journal of Higher Education, 89(6), 807-831. doi:10.1080/00221546.2018.1442983

$\mathrm{Xu}, \mathrm{D} . \& \mathrm{Xu}, \mathrm{Y} .(2019)$. The promise and limits of online higher education: Understanding how distance education affects access, cost and quality. American Enterprise Institute. Retrieved from https://tacc.org/sites/default/files/documents/2019-03/the-promisesand-limits-of-online-higher-education.pdf 